19 Revue d'histoire du XIXe siècle

Société d'histoire de la révolution de 1848 et des

révolutions du XIXe siècle

$4 \mid 1988$

Varia

\title{
Mâcon honore Lamartine. Une mosaïque monumentale à Mâcon consacrée au Gouvernement provisoire de 1848 et au "Banquet des girondins" du 18 juillet 1847
}

Jean-Amédée Lathoud

\section{(2) OpenEdition}

\section{Journals}

Electronic version

URL: http://journals.openedition.org/rh19/29

DOI: $10.4000 /$ rh 19.29

ISSN: $1777-5329$

Publisher

La Société de 1848

Printed version

Date of publication: 1 June 1988

ISSN: 1265-1354

Electronic reference

Jean-Amédée Lathoud, « Mâcon honore Lamartine. Une mosaïque monumentale à Mâcon consacrée au Gouvernement provisoire de 1848 et au "Banquet des girondins" du 18 juillet 1847 », Revue d'histoire du XIXe siècle [Online], 4 | 1988, Online since 09 September 2008, connection on 03 May 2019. URL http://journals.openedition.org/rh19/29; DOI : 10.4000/rh19.29

This text was automatically generated on 3 May 2019.

Tous droits réservés 


\section{Mâcon honore Lamartine. Une mosaïque monumentale à Mâcon consacrée au Gouvernement provisoire de 1848 et au "Banquet des girondins" du 18 juillet 1847}

Jean-Amédée Lathoud

\section{ABSTRACTS}

No abstract available by now

Pas de résumé disponible actuellement

INDEX

Mots-clés: 1848, Mâcon, Lamartine 